JRIT

15,2

Received 30 June 2021 Revised 28 August 2021 Accepted 12 September 2021

\section{Applying e-learning system for engineering education - challenges and obstacles}

\author{
El-Shaimaa Talaat Abumandour
Bibliotheca Alexandrina, Alexandria, Egypt \\ El-Shaimaa Talaat Abumandour
Information Institutions and Professional Skills Department,
Bibliotheca Alexandrina, Alexandria, Egypt \\ El-Shaimaa Talaat Abumandour
Bition Institutions and Professional Skills Department,
Bibliotheca Alexandrina, Alexandria, Egypt
}

\begin{abstract}
Purpose - At present, humankind is facing rapid and profound changes in society, science, technology,
economy and environment. The 21 st century has witnessed extraordinary scientific and technological
progressions. Improvement of technology has generated new educational technique known as e-learning.
Nowadays, popularity of e-learning is growing rapidly and numerous educational organizations, public,
academic and digital libraries are embracing it. Lately, engineering education is heading toward the blended
education system as it successfully combines both chalk and talk system (face-to-face), computer-assisted
Abstract
Purpose - At present, humankind is facing rapid and profound changes in society, science, technology,
economy and environment. The 21 st century has witnessed extraordinary scientific and technological
progressions. Improvement of technology has generated new educational technique known as e-learning.
Nowadays, popularity of e-learning is growing rapidly and numerous educational organizations, public,
academic and digital libraries are embracing it. Lately, engineering education is heading toward the blended
education system as it successfully combines both chalk and talk system (face-to-face), computer-assisted

Abstract
Purpose - At present, humankind is facing rapid and profound changes in society, science, technology,
economy and environment. The 21 st century has witnessed extraordinary scientific and technological
progressions. Improvement of technology has generated new educational technique known as e-learning.
Nowadays, popularity of e-learning is growing rapidly and numerous educational organizations, public,
academic and digital libraries are embracing it. Lately, engineering education is heading toward the blended
education system as it successfully combines both chalk and talk system (face-to-face), computer-assisted

Abstract
Purpose - At present, humankind is facing rapid and profound changes in society, science, technology,
economy and environment. The 21st century has witnessed extraordinary scientific and technological
progressions. Improvement of technology has generated new educational technique known as e-learning.
Nowadays, popularity of e-learning is growing rapidly and numerous educational organizations, public,
academic and digital libraries are embracing it. Lately, engineering education is heading toward the blended
education system as it successfully combines both chalk and talk system (face-to-face), computer-assisted

Abstract
Purpose - At present, humankind is facing rapid and profound changes in society, science, technology,
economy and environment. The 21 st century has witnessed extraordinary scientific and technological
progressions. Improvement of technology has generated new educational technique known as e-learning.
Nowadays, popularity of e-learning is growing rapidly and numerous educational organizations, public,
academic and digital libraries are embracing it. Lately, engineering education is heading toward the blended
education system as it successfully combines both chalk and talk system (face-to-face), computer-assisted

Abstract
Purpose - At present, humankind is facing rapid and profound changes in society, science, technology,
economy and environment. The 21st century has witnessed extraordinary scientific and technological
progressions. Improvement of technology has generated new educational technique known as e-learning.
Nowadays, popularity of e-learning is growing rapidly and numerous educational organizations, public,
academic and digital libraries are embracing it. Lately, engineering education is heading toward the blended
education system as it successfully combines both chalk and talk system (face-to-face), computer-assisted

Abstract
Purpose - At present, humankind is facing rapid and profound changes in society, science, technology,
economy and environment. The 21 st century has witnessed extraordinary scientific and technological
progressions. Improvement of technology has generated new educational technique known as e-learning.
Nowadays, popularity of e-learning is growing rapidly and numerous educational organizations, public,
academic and digital libraries are embracing it. Lately, engineering education is heading toward the blended
education system as it successfully combines both chalk and talk system (face-to-face), computer-assisted learning methodologies and internet access feature to learners.

Design/methodology/approach - This work discusses the potential of e-learning as an educational system for engineering topics and the challenges faced by educational organizations and public libraries as their partners in applying this system for engineering topics. In addition, number of national and international successful engineering e-learning trials that have been created, organized and/or hosted by educational organizations and public libraries are presented.

Findings - The author presents challenges and obstacles that stakeholders, teachers, professors and librarians should be aware of to develop and support the e-learning system. Hence, a number of recommendations are provided to build a bridge linking e-learning and engineering education.

Originality/value - This paper is a complementary work to a previously published study. In this paper, the author sheds light on the link between the e-learning system and the engineering education provided by the educational organizations and hosted by public libraries.

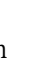

Keywords E-learning, Engineering education, Public libraries, STEM

Paper type Research paper

\section{Introduction}

Since the dawn of history, science, mathematics and engineering learning has been admired among students, researchers and philosophers. These topics have contributed in shaping the progress of humankind civilization. Man has worked on developing learning techniques starting from engravings on clay and stone, reaching to writing on papyrus and paper. The industrial revolution was a huge wave of change upon all human activities and aspects. Technology witnessed outstanding progress. In accordance, the information and communication technology (ICT) field has been widely advanced. The integration of science and technology produced an innovative educational method called e-learning. "E-learning" is a term that refers to electronic or virtual learning method. This method of learning usually supports the traditional educational system. Nevertheless, it is an independent system, and it could provide a rich learning experience totally online. Earlier, teachers, lecturers and professors played the role of knowledge and information source and

(c) El-Shaimaa Talaat Abumandour. Published in Journal of Research in Innovative Teaching \& Learning. Published by Emerald Publishing Limited. This article is published under the Creative Commons Attribution (CC BY 4.0) licence. Anyone may reproduce, distribute, translate and create derivative works of this article (for both commercial and non-commercial purposes), subject to full attribution to the original publication and authors. The full terms of this licence may be seen at http://creativecommons. org/licences/by/4.0/legalcode
Journal of Research in Innovative Teaching \& Learning Vol. 15 No. 2,202 pp. $150-169$ Emerald Publishing Limited 2397-7604

DOI 10.1108/JRIT-06-2021-0048

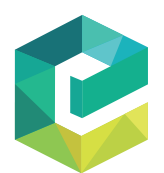


spreader. Nowadays, the role of teacher, lecturer and professor has been altered to be a mentor, facilitator and/or a coach. E-learning is an emergent and promising educational method. Recently, e-learning attracts more attention because of its favorable characteristics. It promotes lifelong learning and self-paced education. It is not limited by students' or learners' gender or location. Additionally, learners could access educational materials anywhere anytime 24/7. In early 2020, the whole world faced a serious challenge as the COVID-19 pandemic emerged. Most of the educational organizations worldwide were closed. During the pandemic crisis, a sudden shift from traditional learning (face-to-face) to e-learning system was adopted in many parts of the globe. The COVID-19 pandemic crisis was an inflection point for the dissemination and rapid implementation of the e-learning educational system. Engineering education is one of the applied disciplines that requires a hands-on laboratory and experiences design. Nevertheless, e-learning could provide virtual laboratories, simulations and experimental workshops to learners. E-learning could provide formal and informal engineering education for different categories of learners not limited to age or specialty, this topic will be discussed in detail later on.

Engineering education is one of the STEM fields that has been always dependent on the educational content, hands-on activities, lab-based work, design and simulation-oriented. Engineering educational has been traditionally focused on developing critical thinking, problem solving and creativity. Engineers, academia and researchers always search and develop novel pedagogical methods and techniques. They mainly focus on improving the engineering educational process including interactive learning, peer education and projectbased learning (PBL) (Asgari et al., 2021).

Asgari et al. (2021) have conducted an observational case study at California State University in order to assess the university's e-learning engineering educational experience during the pandemic. The research team identified various factors that hinder e-learning engineering education such as technical drawbacks, teaching problems, security issues and lack of practical and lab-based training. On the other hand, the study showed that the percentage of cheating observation decreased when instructors used fully online and/or openbook exams style. Asgari et al. (2021) recommended further studies and international cooperation between the educational organizations to improve e-learning in engineering education.

Nowadays, ICT plays a great role in the educational process. The educational sector has witnessed great changes in:

(1) the educational materials provided;

(2) the methods of content delivery; and

(3) the interactive technologies used.

Various educational organizations and/or research institutions have embraced these changes in various fields to enhance the learning and teaching process, improve students' performance, ensure their commitment and satisfaction (Violante et al., 2019). Violante et al. (2019) have designed an interactive learning technique based on $360^{\circ}$ videos. The research team has applied this method in an engineering program, but, they recommend using this method in any industrial or educational context. Researchers stated that the $360^{\circ}$ videos are a new type of shooting that enables learners to see the video-recorded scene from all directions. This method provides quite an engaging experience to users. They concluded that $360^{\circ}$ video enhances the learners' problem-solving competency, increases their understanding of the topics covered and, in the meantime, increases their enjoyment and pleasure during the visualization of the $360^{\circ}$ videos. In this context, Checa and Bustillo (2020) presented two teaching methodologies semi-guided tours in immersive virtual reality (VR)
Engineering education challenges using e-learning 
JRIT

15,2

152

and viewing video renderings of $3 \mathrm{D}$ environments. The research has evaluated the experience of using VR techniques for teaching various topics especially related to cultural heritage.

On the other hand, Violante et al. (2020) studied a learning outcomes-based method to provide a cumulative assessment to be used for any topic at any educational level. Researchers took into consideration the European Qualifications Framework to define the learning outputs, Bloom's taxonomy to identify assessment queries and the QR code to handle large class capacity. The method has been implemented on the technical drawing course provided by the Faculty of Engineering in Italy for the BSc Engineering Program. The new assessment method was analyzed during two academic years and has shown promising results in terms of increasing students' success percentages, decreasing failure percentage and reducing of time consumed in uploading marks via the electronic register. Svensson et al. (2020) studied the engineering pedagogy from another perspective which is entrepreneurial engineering its models, tradeoffs and discourses. The study has identified three pedagogical methods for improving the entrepreneurial experience in engineering teaching.

Public libraries are embassies of knowledge and information nationally and internationally. They play a great role in spreading knowledge via their various resources, activities and services. Public libraries could be a potential partner to educational organizations in supporting the e-learning educational system. Public libraries are lighthouses that could change and improve the community. From the ancient to modern, the Bibliotheca Alexandrina (BA) (Library of Alexandria) has played an exceptional role as an open university and a research hub. The main target of the modern library is to be a hub of merit in acquaintance creation and spreading. In addition, BA aspires to be the destination of interchange, learning, tolerance and understanding. The BA was one of the pioneer public libraries that have launched online educational services. The aim of the emergent BA e-learning service is to provide courses, trainings, modules and certified degrees to users from all over the world.

The aim of this paper is to shed light on the potential of the e-learning in supporting engineering topics. Additionally, this study highlights the challenges and difficulties that educational organizations and their academic staff are facing. Public libraries are promising partners and supporters for the educational organizations to embrace, develop and disseminate the e-learning education system and lifelong education literacy.

\section{Literature review}

This section will review some of the definitions and facts that were published in literature to help readers to follow up the topic. The e-learning education system was defined by various authors in published literature. It is a web-enabled system that offers educational content in various media to different audiences anytime anywhere (Abumandour, 2020). There are different terms defining e-learning such as web-based, virtual, computer-based, web-enabled, online education and so on. Kumbhar (2009) defined e-learning as a learning system supported by technology. It depends on computer devices, smart devices, networks, telecommunication, sharing, storage technology and virtual meeting tools. Furthermore, the National Science Teachers Association (NSTA) (2016) stated that e-learning could play a pivotal role in improving science and technology education. Recently, e-learning covers numerous topics and fields; starting from LIS to engineering sciences, which will be discussed in detail later. Fernandez-Rodriguez et al. (2013) conducted research about engineering education using e-learning system in Spain highlighting the good evaluation results of the students participated in the investigated project. They stated that e-learning system is efficient to be applied in all engineering areas. E-learning in engineering education was investigated by Benchicou et al. (2010) in Algeria as a developing country. The authors referred success of the implemented e-learning program in higher institutions to set of critical factors which include: 
(1) The strategy that will be adopted by the higher educational institutions;

(2) The faculty members' adherence to the system, understanding and developing; and

(3) The willingness of the higher educational institution to offer adequate support to the system (trainings to staff, improving platform, system assessment).

Anis (2011) presented the implementation of e-learning in engineering education from an Egyptian perspective. He stated that the major challenge confronting the application of e-learning in engineering education is the need for laboratories as in campus-based curriculum. In this study, the author points out that for engineering programs that use elearning, laboratories could be designed as simulative lab or remotely controlled physical laboratories.

As mentioned above, public libraries have an essential role in supporting e-learning education for different subjects such as STEM. Nevertheless, this statement has not yet been fully discussed by research, especially in developing countries. Abumandour (2020) has conducted research about the role of public libraries in spreading and supporting the e-learning system. The author presented the BA as a case study. She stated that public libraries have enormous capabilities that empower them to be a gateway toward e-learning. They should approve the quality of the provided educational material and services. Additionally, public libraries should work on distributing their services equally to all types of public users.

\section{Methodology}

This study's main concern is to measure the willingness of the Egyptian educational system to implement the e-learning approach as a promising learning method for all fields. A special concern is given to Egyptian and international engineering e-learning educational trials. Using published literature, official universities, research organizations and public libraries' websites, data were collected. The collected data were e-courses provided by different national and international educational organizations, public libraries and hosted by different LMS platforms. In this study, data were clustered based on three criteria: the selected e-course should cover one of the engineering disciplines, should have a high rating and great reviews and should be provided by a distinguished educational organization or/and a public library. The list of the e-courses is shown in the supporting information Tables 1 and 2.

The main purpose of gathering the data was to perform an empirical study that applies both qualitative and quantitative approaches in order to address the research question. The qualitative and quantitative case-study approaches are warranted when the study focuses on the engineering fields covered by the e-learning system and the percentage of each field comparing to others, respectively. A selective sampling strategy was used to choose specific e-courses and their associated providers. The number of the selected e-courses was \pm 230 provided by eminent national and international educational organizations, and all covered engineering disciplines. The selected e-courses were classified into three categories: engineering e-courses provided by Egyptian universities, international universities and e-courses provided by the BA. In keeping with the research question, the data were investigated and analyzed.

\section{Results}

In this section, the author has selected a sample of different engineering e-courses that are relevant to the vision of the study. The author was wholehearted to present national and international efforts that have been made to apply e-learning techniques to engineering 
JRIT

15,2

154

\begin{tabular}{|c|c|c|c|c|}
\hline University Name & Faculty Name & Discipline & Topic & Audience \\
\hline \multirow{39}{*}{ Cairo University } & \multirow{39}{*}{$\begin{array}{l}\text { Faculty of } \\
\text { Engineering }\end{array}$} & $\begin{array}{c}\text { Fundamental } \\
\text { Engineering }\end{array}$ & History of Engineering Sciences & \multirow{39}{*}{ Undergraduates } \\
\hline & & \multirow{14}{*}{$\begin{array}{l}\text { Electrical Power } \\
\text { Engineering }\end{array}$} & Electrical Materials & \\
\hline & & & Laboratory & \\
\hline & & & Industrial Control & \\
\hline & & & Control of Industrial Processes & \\
\hline & & & Introduction to Civil Engineering & \\
\hline & & & Special Topics in High Voltage Engineering & \\
\hline & & & Digital Electronics \& Micro-pro-processors & \\
\hline & & & High Voltage Engineering & \\
\hline & & & Signals and Systems & \\
\hline & & & Digital Control & \\
\hline & & & B.Sc. Graduation Project 2008-2009 & \\
\hline & & & Computer Applications & \\
\hline & & & Control Systems - A & \\
\hline & & & Electromagnetics (Electrostatics) & \\
\hline & & \multirow{24}{*}{ Chemical Engineering } & Introduction to Chemical Engineering & \\
\hline & & & Inorganic and Analytical Chemistry & \\
\hline & & & Phase Equilibria & \\
\hline & & & Momentum Transfer & \\
\hline & & & Physical Chemistry & \\
\hline & & & Organic Chemistry & \\
\hline & & & Fundamentals of Chemical Engineering & \\
\hline & & & Materials Engineering & \\
\hline & & & Process Safety or Management & \\
\hline & & & Heat transfer & \\
\hline & & & Electrochemistry for Chemical Engineers & \\
\hline & & & Mechanical Unit Operations & \\
\hline & & & Inorganic Technology & \\
\hline & & & Petroleum Refining & \\
\hline & & & Mass Transfer & \\
\hline & & & Chemical Process Control & \\
\hline & & & Acrylic Acid Project & \\
\hline & & & Petroleum Process Engineering & \\
\hline & & & Environmental Engineering & \\
\hline & & & Reactor and Vessel Design & \\
\hline & & & Nuclear Engineering & \\
\hline & & & Economics & \\
\hline & & & New Materials & \\
\hline & & & Chemical Engineering Lab & \\
\hline
\end{tabular}

Table 1.

Engineering e-courses provided by Egyptian universities 


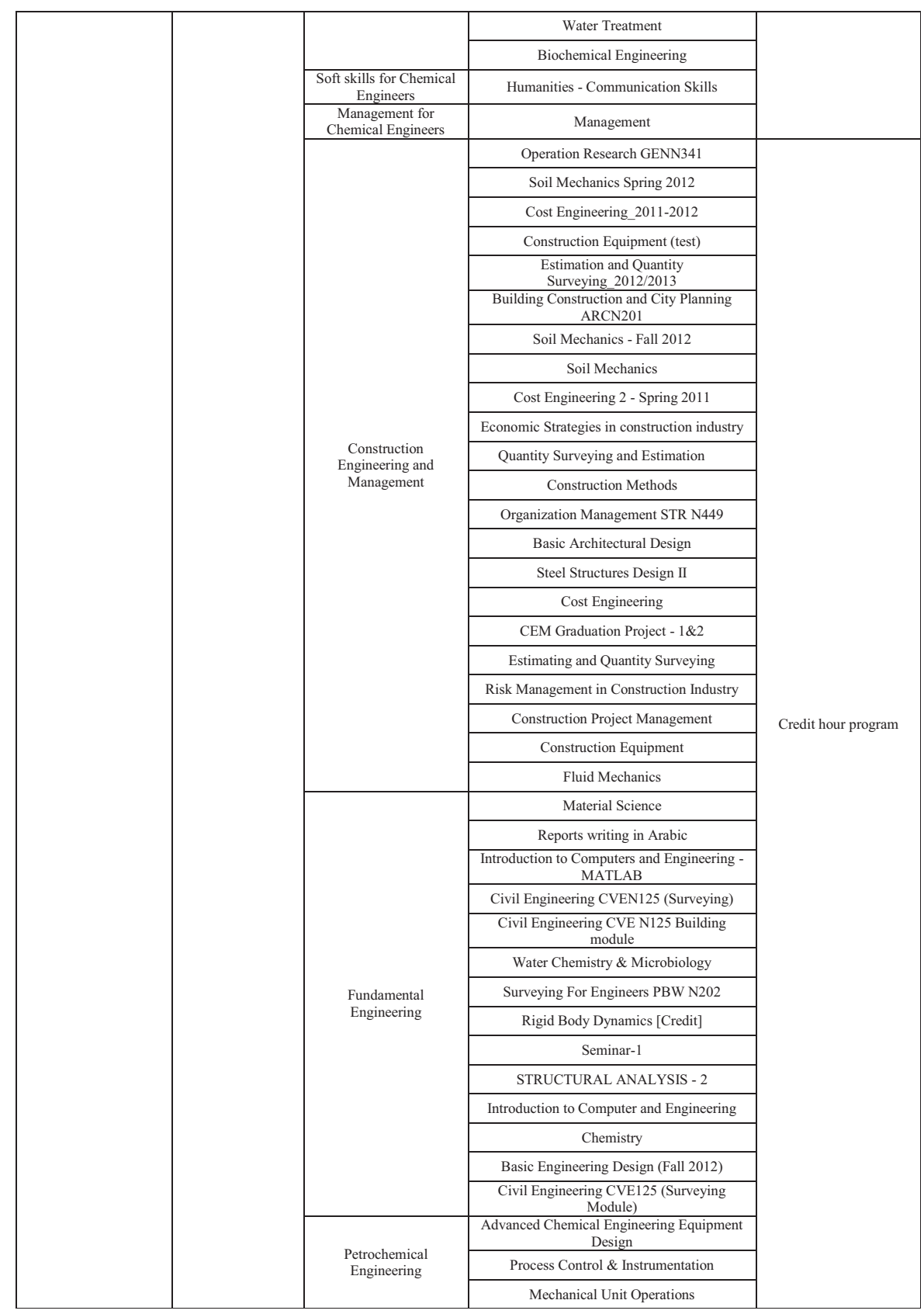

Engineering education challenges using e-learning

155 
Table 1. 


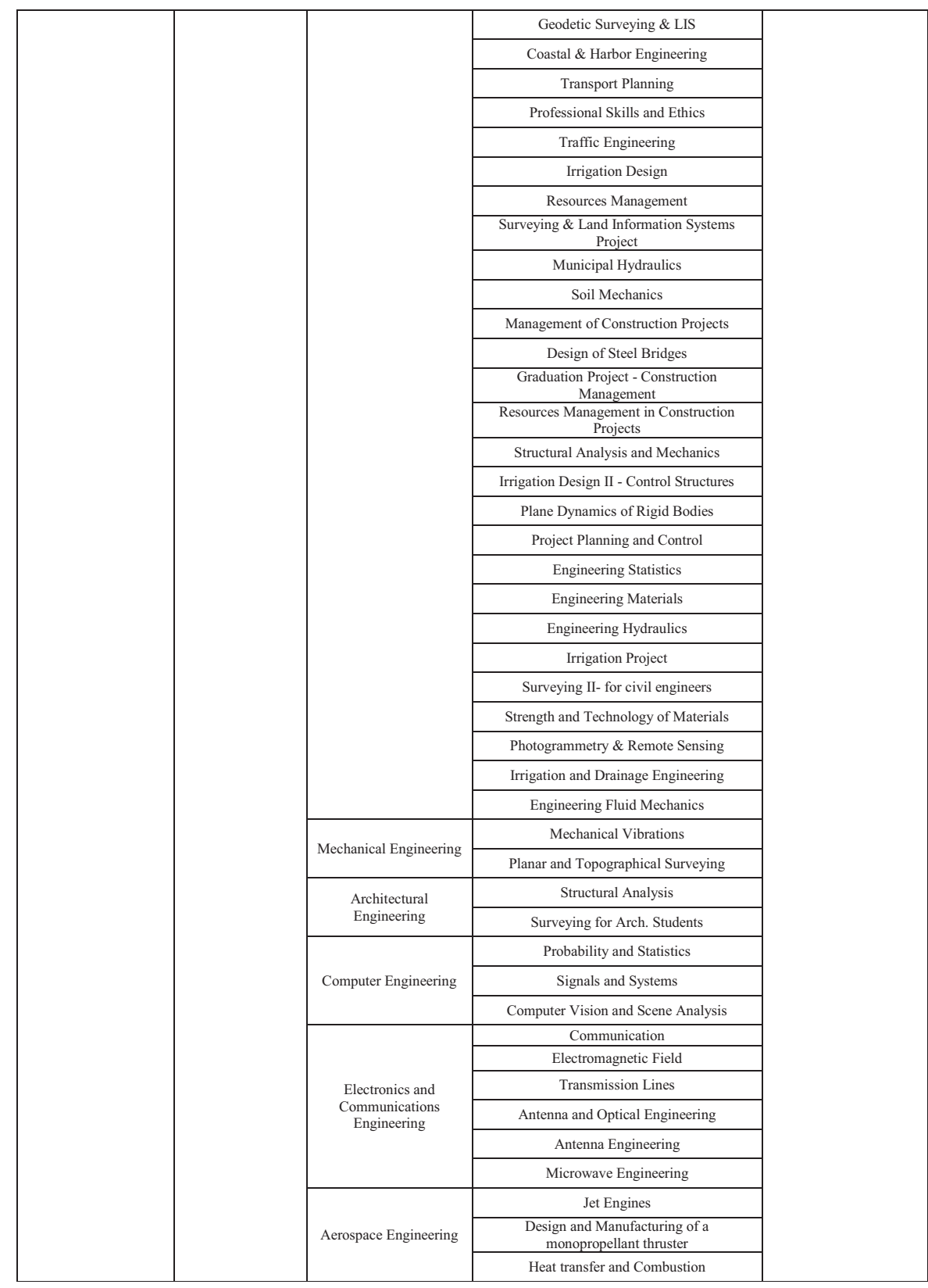

Engineering

education

challenges

using e-learning

157 
Table 1. 


\begin{tabular}{|c|c|c|c|c|}
\hline & & & Technical Writing - MSc Students & \\
\hline & & & Free Software and Online Tools & \\
\hline & & \multirow{4}{*}{$\begin{array}{l}\text { Risk Engineering } \\
\text { Diploma }\end{array}$} & Natural Risk Assessment & \\
\hline & & & Industrial Risk Assessment & \\
\hline & & & Project and Risk Engineering Management & \\
\hline & & & Elective Course & \\
\hline & & \multirow{26}{*}{ Structural Engineering } & Computational Hydraulics & \\
\hline & & & Soil Dynamics & \\
\hline & & & Advanced Soil Mechanics & \\
\hline & & & Time Series Analysis & \\
\hline & & & Design of Pipe Lines \& Pumping Station & \\
\hline & & & Stochastic Hydrology & \\
\hline & & & Water Resources Systems & \\
\hline & & & $\begin{array}{c}\text { Programming Language and Numerical } \\
\text { Analysis }\end{array}$ & \\
\hline & & & Advanced Hydraulics Engineering & \\
\hline & & & Pipelines and Pumping Stations & \\
\hline & & & River Engineering & \\
\hline & & & Technical Writing and Communication Skills & \\
\hline & & & Computational Hydraulics & \\
\hline & & & Optimization and Decision Making & \\
\hline & & & Design of RC Structures under Lateral Loads & \\
\hline & & & Seismic Behavior of Steel Structures & \\
\hline & & & Cost Estimate and Control & \\
\hline & & & $\begin{array}{l}\text { Inspection, Maintenance, and Repair of Steel } \\
\text { Structures }\end{array}$ & \\
\hline & & & Risk Management - M.Sc. (CEM) & \\
\hline & & & High Rise Steel Building & \\
\hline & & & $\begin{array}{c}\text { Strength and Technology of Construction } \\
\text { Materials }\end{array}$ & \\
\hline & & & Selected Topics in Construction & \\
\hline & & & Construction Management & \\
\hline & & & Report Writing & \\
\hline & & & Numerical Analysis & \\
\hline & & & Structural Analysis of Highway Bridges & \\
\hline & & Aerospace Engineering & Numerical methods in propulsion & \\
\hline & & Flectronics and & Moment Method & \\
\hline & & Communications & Advanced Engineering Electromagnetics & \\
\hline & & & Optimal Control Theory & \\
\hline & \multirow{4}{*}{$\begin{array}{l}\text { Faculty of } \\
\text { Computer and } \\
\text { Information }\end{array}$} & \multirow{4}{*}{$\begin{array}{l}\text { Information and } \\
\text { Communication } \\
\text { Technology }\end{array}$} & EELU- Programming Techniques 3 & \multirow{7}{*}{ Undergraduates } \\
\hline & & & Concepts of Programming Languages & \\
\hline & & & Data Structure & \\
\hline & & & Programming & \\
\hline \multirow{3}{*}{ Ain Shams University } & \multirow{3}{*}{$\begin{array}{l}\text { Faculty of } \\
\text { Engineering }\end{array}$} & \multirow{3}{*}{ Engineering Hydrology } & Irrigation design & \\
\hline & & & Engineering Hydrology & \\
\hline & & & Engineering Hydrology & \\
\hline
\end{tabular}

Engineering education challenges using e-learning

159

Table 1. 


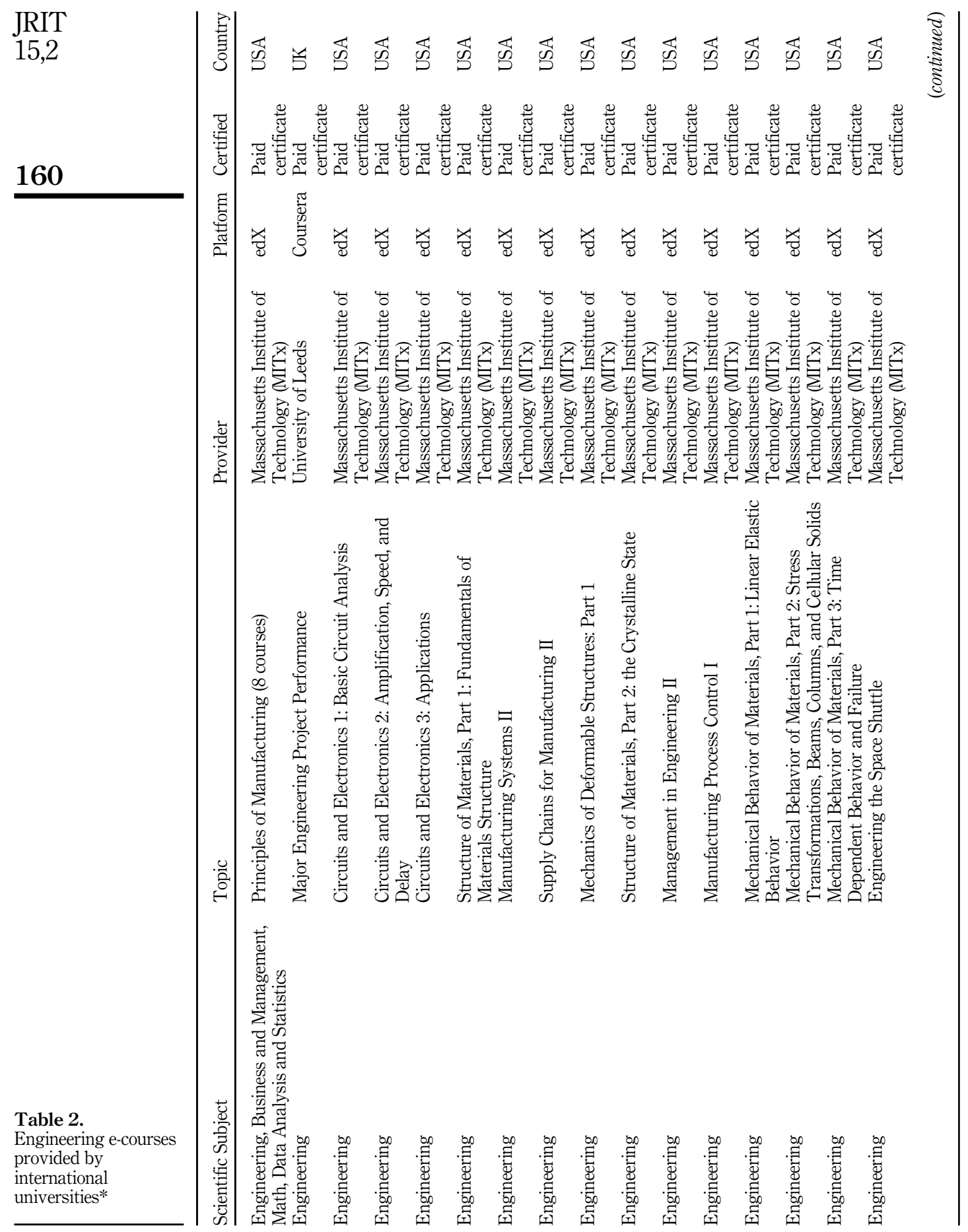




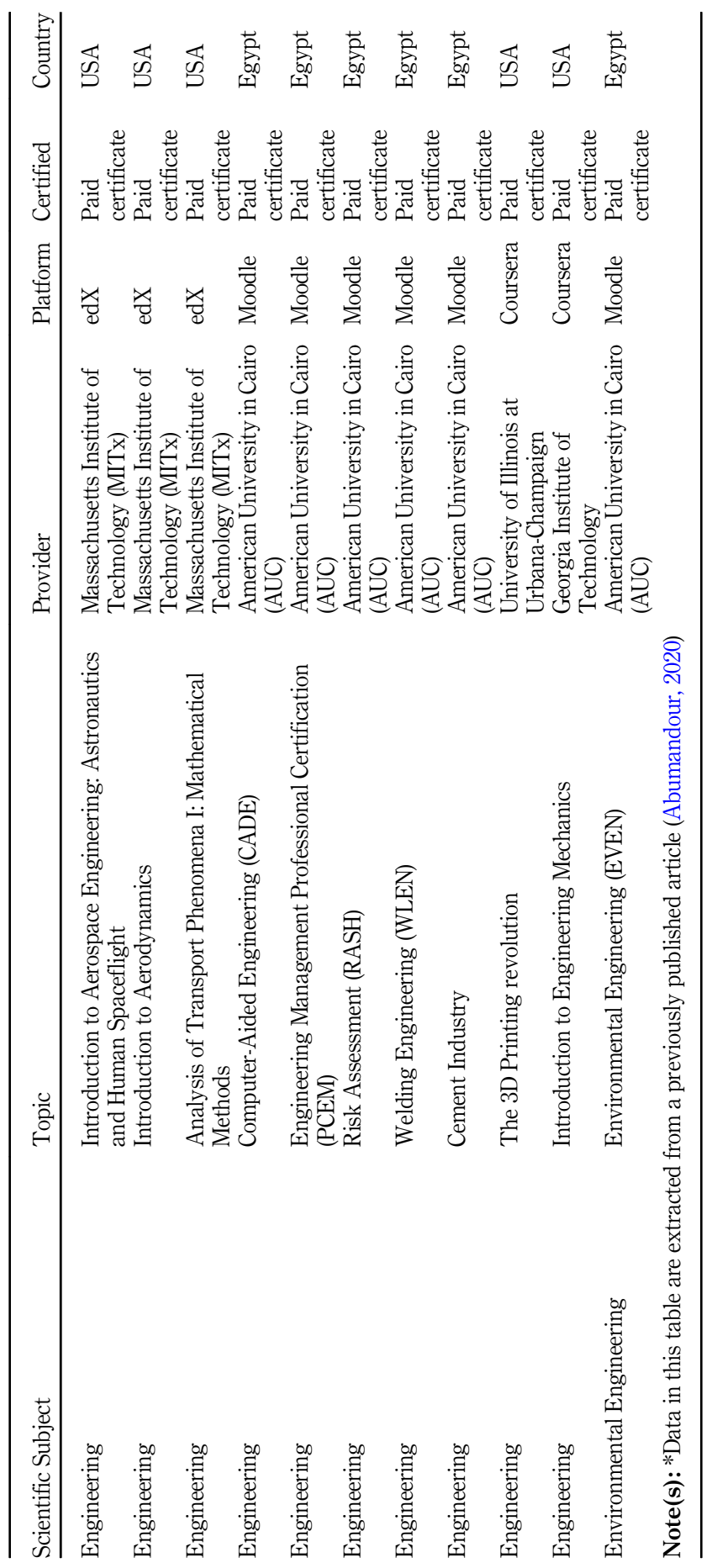

Engineering education challenges using e-learning

161

Table 2. 
JRIT

15,2

162

education. Table 1 shows more than 250 online courseware materials in all engineering disciplines provided by prestigious Egyptian universities such as Cairo University. Table 2 shows the number of engineering e-courses provided by international well-known universities. These data were extracted from a previously published article (Abumandour, 2020). In addition, the public libraries' roles in spreading and supporting e-learning were highlighted by presenting the BA model, as a national example, and Toronto public library, as an international example.

\section{Universities effort in providing engineering e-courses}

The list of the online courseware is shown in the supporting information Table 1, and the number of e-courses presented is 253 . The chosen e-courses are offered by two eminent Egyptian universities, $98.8 \%$ of the e-courses provided by Cairo University and $1.1 \%$ by Ain Shams University. The e-courses are covering most of the engineering disciplines such as Fundamental Engineering, Chemical Engineering and Electrical power engineering. Figure 1 shows the audience targeted by the engineering e-courses provided by Egyptian universities. The covered e-courses are provided by the Faculty of Engineering and Faculty of Computer and Information as a supplementary to traditional (campus-based) courses. All the listed online courses are presented using the Moodle platform. Moodle platform was adopted because it is an open-source learning management system (LMS). Figure 2 shows the international universities providing engineering e-courses with the following percentage: Massachusetts Institute of Technology (MITx) 85\%, University of Leeds $5 \%$, the University of Illinois at Urbana-Champaign 5\% and Georgia Institute of Technology $5 \%$ of the covered

Figure 1.

Audience percentage of the engineering online courseware provided by Egyptian universities
Figure 2. International universities providing engineering e-courses
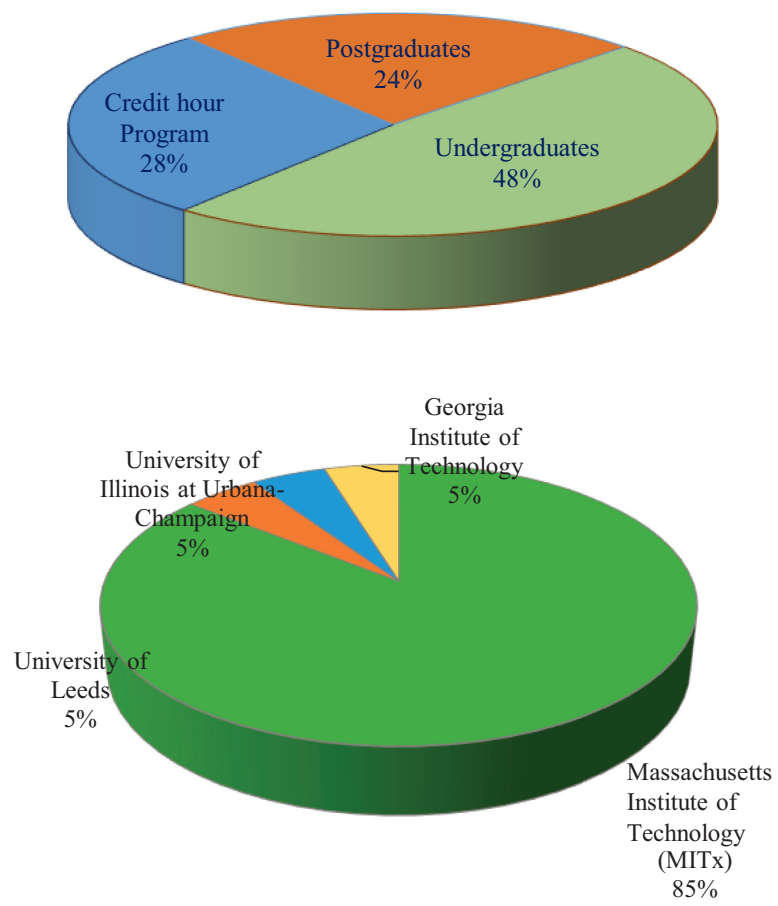
e-courses. Table 2 in the supporting information lists number of engineering e-courses provided by international universities.

\section{Public libraries role in supporting e-learning}

The BA launched its e-learning service in early 2017. The main target of this emergent service is to provide educational materials for all the BA users (specifically all over Egypt, Africa, the Arab World and generally the whole world). The BA e-learning services focus on presenting different topics to users who are geographically isolated from educational organizations and during tough time such as the quarantine and pandemic periods. Since 2017, the BA e-learning services have successfully delivered various e-courses categorized according to learners' competencies (general and lifelong learners, undergraduates, postgraduates and researchers). The BA e-learning services platform includes free and accredited online e-courses that provide learners with a wide range of academic topics. The e-courses listed in Table 3 in the supporting information (Abumandour, 2020) are considered massive open online courses which mean that any interested learner could participate in the e-course. Most of the listed e-courses do not require prerequisites or specific qualifications to join. Nevertheless, some advanced e-courses would expect that learners have a certain level of knowledge in the discussed area. BA improves its e-learning resources, techniques and content indoors depending on its talented and highly qualified staff, and through cooperation with various national, international educational organizations and institutions; this point will be discussed in detail in the discussion section.

Toronto Public Library provides massive e-learning content. Most of the presented e-courses cover ICT topics and are presented in English for adult users. It is noticeable from the official website of the library that most of the e-courses delivered in early 2020 till today are related to public health, public awareness and topics related to COVID-19.

\section{Discussion}

After the industrial revolution, it was clear that both science and technology have an impressive impact upon all human activities. The achieved progress in both fields has a direct influence on industry, economy, trade, health and education. The 21st century could be considered a technological epoch. Technology has transformed and modernized the educational field. The technology could transform education from a passive, uninteresting process to an interactive and interesting experiment. Raja and Nagasubramani (2018) stated that technology supports the educational field by creating interactive content, delivering this content via an instructional system and organizing the whole process. In brief, technology usually assists learners and/or students to comprehend and recall concepts easier. Therefore, the demand for innovative and advanced educational systems grows (Abumandour, 2020; Chetty, 2012; Eagleton and Manolopoulou, 2017). The increasing demand for new and interactive techniques and the developed ICT produced the e-learning system. Nowadays, researchers, scientists, engineers and professors face a great challenge, to continue researching, innovating and at the same time coping with the hectic expansion and continuous progress of technology. In addition, they have a sacred mission of teaching, disseminating and mentoring students and/or learners. Therefore, e-learning attracts more attention lately, as a promising educational system.

Generally, e-learning system relies on three major factors, these factors are organized and governed by educational organizations and/or public libraries and have a direct impact on recipients (students and/or learners) as shown in Figure 3 (Abumandour, 2020; Benchicou et al., 2010). These factors are interactive content (presentation, audio, video, softcopy manuscripts, etc.), the instructor (mentor, lecturer, teacher) and technological tools.
Engineering education challenges using e-learning 


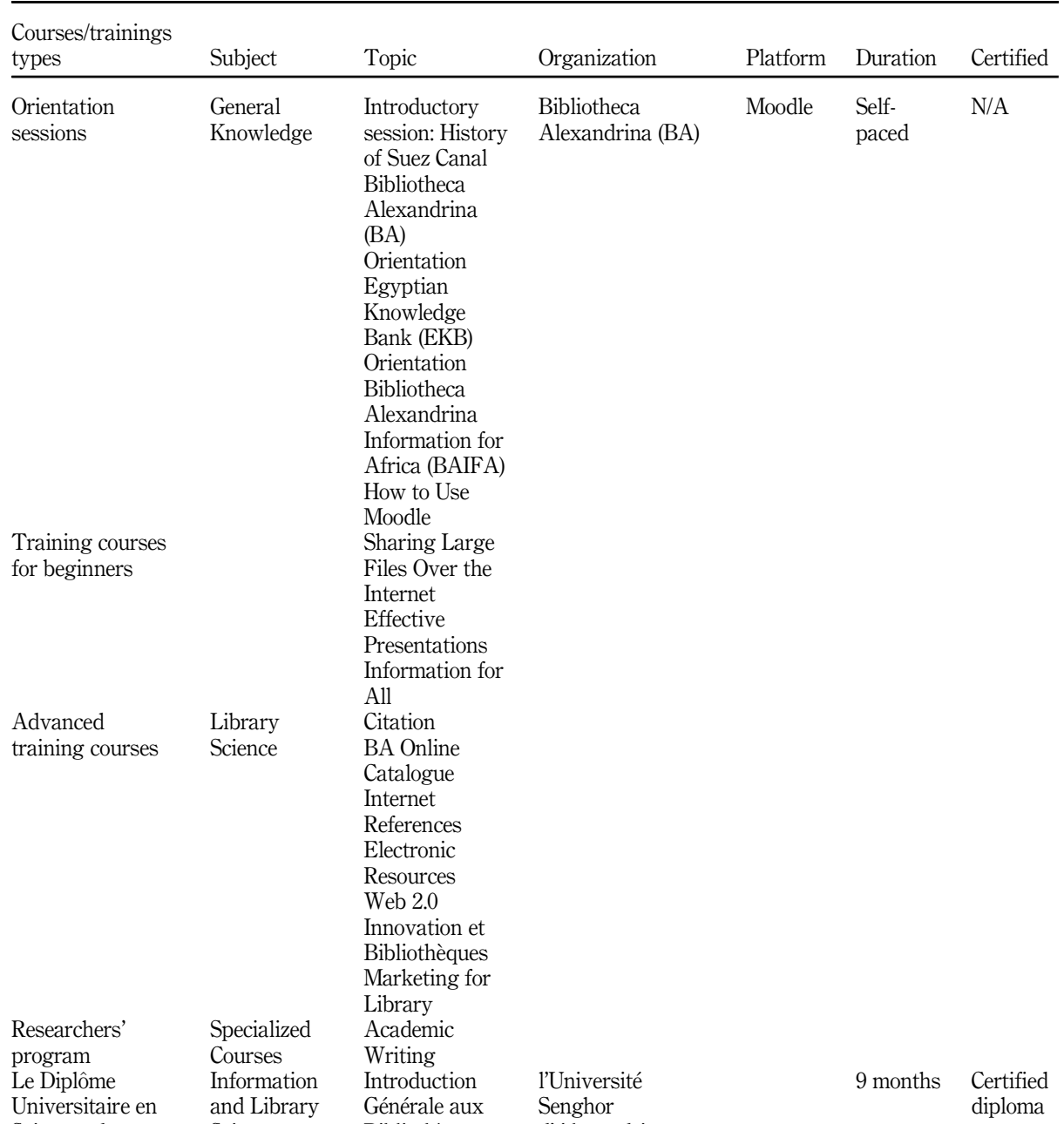

Table 3.

E-courses included in the BA e-learning services platform*
Sciences de

l'Information et

des Bibliothèques

(DUSIB

Programme)

\section{Sciences}

Bibliothèques

Gestion du

Patrimoine

Audiovisuel

Droit de la

Propriété

Intellectuelle

Médiation et

Ingénierie

Culturelle
d'Alexandrie,

l'Ecole Nationale

Supérieure des

Sciences de

l'Information et des

Bibliothèques

(Enssib), la

Bibliotheca

Alexandrina (BA),

et la Bibliothèque

nationale de France

(BnF), avec l'appui

de l'Association des

Amis de la

Bibliotheca

Alexandrina

Note(s): *Data in this table are extracted from a previously published article [1] 


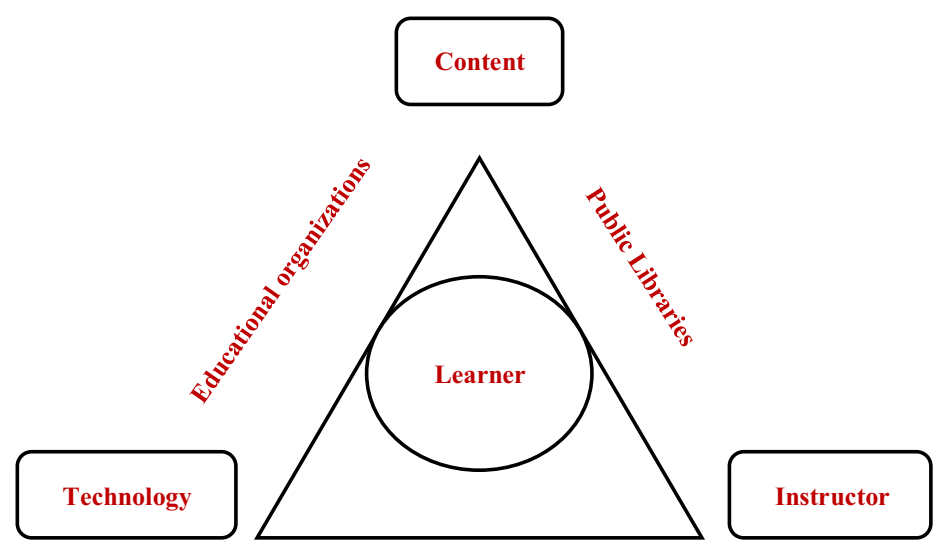

\section{Engineering education challenges using e-learning}

165

Figure 3.

The essential elements of e-learning

The LMS is a software application that carries e-courses materials and offers different techniques such as designing, documenting, evaluating and transforming courses into interesting and interactive e-material.

\section{Egyptian universities effort in providing engineering e-courses}

The author has discussed the e-learning of Science, Technology, Engineering and Mathematics (STEM) education, in general, in a previously published article (Abumandour, 2020). This study focused on e-learning engineering education as it has gained widespread appreciation as the main driver of progress and has a direct impact on life quality enhancement (Dordevic and Snezana, 2016). Engineering education is one of the topics that depend on lab-based work and hands-on training. Engineering education has always been dependent on tutors as the disseminator of knowledge and students' attendance, nevertheless, the recent enormous progress in ICT has permitted e-learning to use various tools and techniques that enhance and facilitate engineering education. E-learning or distance learning system is adopted lately by most educational organizations and public libraries globally as such a virtual method spreading lifelong education and enabling learners to access the content anytime anywhere. In engineering education, e-learning is being promptly embraced by most universities worldwide, as the lab-based work and hands-on methods could be met through online education [Accreditation Board for Engineering and Technology (ABET), 2009].

Anis (2011) stated that many Egyptian scholars are lately convinced that undergraduate engineering standards could be achieved online similar to campus laboratories. He added that e-learning could be an assisting method to the traditional educational method because it offers updated technologies that would be of great help to education.

From the collected data, it is obvious that engineering education via e-learning has become popular, covering mostly all topics and delivered by well-known educational institutions and/ or organizations globally. The ABET (2009) identified number of competencies that should be attributed to engineering education which are obtainable by e-learning such as:

(1) The capability of applying scientific and mathematical knowledge;

(2) The ability to conduct experiments, collect and interpret data;

(3) The facility to design a system and a process;

(4) Qualifying students to function in interdisciplinary studies;

(5) Providing students with the required knowledge to solve engineering problems; 
JRIT

15,2
(6) Delivering soft skills content to enhance students communication skills;

(7) Introducing professional ethics and safety measures;

(8) Providing lifelong learning opportunities; and

(9) The ability to use up-to-date techniques, methods, skills and emerging engineering tools for engineering practice and providing engineering solutions in a global and social context.

From all the above, it could be concluded that Egyptian universities have successfully implemented the e-learning education system in engineering education. Till today, e-learning could be considered as an accompanying method to the traditional (face-to-face) learning method. Anis (2011) mentioned that Egyptian scholars prefer blended (hybrid) mode of learning because of the academic restrictions toward pure distance engineering education.

\section{Public libraries' role in supporting e-learning}

It was published in literature (Abumandour, 2020; Anis, 2011) that the international and cultural organizations such as the World Bank Group, UNESCO and the Commonwealth are embracing e-learning. Among cultural organizations that played a pivotal role in supporting and promoting e-learning are public libraries. Public libraries have essential elements such as resources, materials, technology and expert staff, which enable them to be a potential key player in developing and disseminating e-learning.

In this paper, two public libraries were taken into consideration, the BA as a national example and Toronto Public Library as an international example.

The role of BA as a public library in supporting and spreading e-learning represents a hybrid model, with its collections, resources, materials, services and activities partially carried out virtually. The BA has launched its online educational service in early 2017 . The BA e-learning services strive to cope with modern technology and to provide e-courses for all users. Over 4 years, the BA e-learning service was able to offer different e-courses covering various topics that could meet the needs of diverse users (general user, LIS specialist, lifelong learner, researcher, postgraduate). The BA collaborated with Senghor University, the National Superior School of Information Science and Libraries (ENSSIB) and the National Library of France $(\mathrm{BnF})$ and provided "DUSIB" as a certified diploma for librarians for three rounds 2018-2019, 2019-2020 and 2020-2021, with the third round launched in November 2020. Since 2019, the BA e-learning service has started to broaden its scope and include new topics that may be useful for a wide range of users such as researchers and postgraduates. Researchers' program is advanced courseware that consists of different modules; each module covers a number of topics that build learners' competencies. This program targets undergraduates, postgraduates and researchers.

In this context, the author would like to highlight the role the BA e-learning services played during the pandemic period. Different online sessions and courses were broadcasted and offered by different tools such as the BA e-learning platform, virtual meeting tools and social media. The online content covered different topics such as academic writing, citation, online meeting applications and presentation design. The responsible team received very good feedback from users concerning these sessions. In brief, the BA is a unique public library providing numerous inventive services. The BA e-learning service develops its output depending on three functional factors:

(1) E-learning expert team that is responsible for creating and providing simple and/or advanced scientific content supporting and developing e-learning techniques, in addition to executing interactive and interesting courseware; 
(2) IT support team to advise the e-learning team and maintain the e-learning system; and

(3) Establishing collaboration between BA and different educational organizations and/ or institutions (schools, universities and research institutions).

Engineering education challenges using e-learning

\section{Challenges and obstacles}

Engineering e-learning education confronts some drawbacks that prevent its wide implementation. These include:

(1) Some educational organizations, institutions and public libraries have feeble IT infrastructure especially in remoteness areas.

(2) Lack of administrative rules that govern the e-learning process.

(3) Some students have limited computer and internet services accessibility in Egypt and other developing countries.

(4) Lack of professional staff with good experience in e-learning technology.

(5) Hard to apply suitable e-learning techniques and tools.

(6) E-learning courseware material preparation is a time-consuming process.

(7) Community (academic, industrial and social) resists any type of learning outside the campus and has no confidence in e-learning engineering education.

\section{Recommendations}

In early 2020, the whole world witnessed swift shutdown for all human activities including educational organizations, institutions, research centers, cultural centers and public libraries. Nevertheless, rapid action was taken by these organizations to shift toward new educational approaches to handle this situation. This tough period has offered priceless new insights into key communication methods and the ways the students learn. This experiment has taught us several things such as:

(1) Combining traditional (face-to-face) and online education for all fields has become essential.

(2) Students have shown great responsibility toward their online learning.

(3) The role of the teachers and academic staff has transformed from a content provider and disseminator to more sacred role of a mentor and a coach.

(4) Teachers and academics should follow-up the novel e-learning techniques.

(5) Traditional education is a precious service that is irreplaceable.

(6) E-learning could support and complement classroom educational system.

(7) Clear criteria and rules should be put to regulate the e-learning process.

(8) Relation between student/learner and teacher/lecturer should be arranged.

(9) There must be definite criteria to evaluate the courseware material.

(10) Educational platforms should be safeguarded.

(11) Educational organizations should enhance their IT infrastructure. 
JRIT

15,2

\section{8}

(12) Educational organizations and public libraries should work on digitalizing scientific materials.

(13) Throughout history public libraries played a great role during crisis and emergencies periods.

(14) Most public libraries are meant to be centers of excellence and knowledge disseminators.

(15) The lockdown period proved that public libraries could support the education whether it is formal or informal learning.

(16) During the lockdown period, public libraries rushed to provide numerous services and resources for education and leisure.

(17) Public libraries proved that they could be partners with educational organizations.

\section{Conclusion}

The engineering field is a very important branch of applied sciences that has a direct influence on human activities and lives. E-learning system has invaded the engineering field. There are massive e-courses covering almost every engineering topic provided by wellknown educational organizations as formal education or informal education. The online courseware materials covering all engineering disciplines target different audiences (lifelong learners, students, undergraduates and postgraduates). National and international public libraries play a great role in supporting e-learning system. Nowadays, there are numerous e-courses and programs that cover different engineering topics executed and published via public libraries' official websites and e-learning platforms. This continuous effort could be a positive sign that public libraries are potential key players in developing, supporting and disseminating the e-learning education system. This role could be achieved when public libraries cooperate with different educational organizations. The conducted study identified challenges and obstacles that engineering e-learning education is facing and may affect its spread worldwide. Various recommendations were proposed to address them. Moreover, the research highlighted the effect of the COVID-19 pandemic influence upon e-learning education in general and engineering e-learning education in particular.

\section{References}

Abumandour, E.S. (2020), "Public libraries' role in supporting e-Learning and spreading lifelong education: a case study", Journal of Research in Innovative Teaching and Learning, Emerald Publishing, Vol. 14 No. 2, pp. 2397-7604, doi: 10.1108/JRIT-06-2019-0063.

Accreditation Board for Engineering and Technology (ABET) (2009), Accreditation Policy and Procedure Manual, Engineering Accreditation Commission Publication, Baltimore, Maryland.

Anis, H. (2011), "E-learning in engineering education - general challenges and the Egyptian experience", Education in a Changing Environment (ECE) 6th International Conference: Creativity and Engagement in Higher Education, 6-8 July 2011, The University of Salford, Greater Manchester, UK, available at: http:/usir.salford.ac.uk/16997/.

Asgari, S., Trajkovic, J., Rahmani, M., Zhang, W., Lo, R.C. and Sciortino, A. (2021), “An observational study of engineering online education during the COVID-19 pandemic", PLoS One, Vol. 16 No. 4, doi: 10.1371/journal.pone.0250041.

Benchicou, S., Aichouni, M. and Nehari, D. (2010), "E-Learning in engineering education: a theoretical and empirical study of the Algerian higher education institution", European Journal of Engineering Education, Vol. 35 No. 3, pp. 325-343, doi: 10.1080/03043797.2010.483610. 
Checa, D. and Bustillo, A. (2020), "Advantages and limits of virtual reality in learning processes: Briviesca in the fifteenth century", Virtual Reality, Vol. 24 No. 1, pp. 151-161, doi: 10.1007/ s10055-019-00389-7.

Chetty, L.R. (2012), "The role of science and technology in developing world in the 21st century", Institute for Ethics and Emerging Technologies, Ethical Technology, available at: https://ieet. org/index.php/IEET2/more/chetty20121003 (accessed 3 December 2018).

Dordevic, M. and Snezana, V. (2016), "Impact of mechanical engineering on quality of life", 1st International Conference on Quality of Life, June 2016, Center for Quality, Faculty of Engineering, University of Kragujevac, Vol. 237, available at: http://cqm.rs/2016/cd1/pdf/ papers/focus_1/34.pdf.

Eagleton, C. and Manolopoulou, A. (2017), "Paper money of England and Wales", available at: https:// www.britishmuseum.org/research/publications/online_research_catalogues/paper_money/ paper_money_of_england_wales/the_industrial_revolution/the_industrial_revolution_3.aspx (accessed 3 December 2018).

Fernandez-Rodriguez, J.C., Javier, R. and Fernando, M.M. (2013), "Engineering education through eLearning technology in Spain", International Journal of Interactive Multimedia and Artificial Intelligence, Vol. 2 No. 1, p. 46, doi: 10.9781/ijimai.2013.216.

Kumbhar, R. (2009), "Use of e-learning in library and information science education", DESIDOC Journal of Library and Information Technology, Vol. 29 No. 29, pp. 37-41, doi: 10.14429/djlit. 29.228 .

National Science Teachers Association (NSTA) Position Statement (2016), "The role of E-learning in science education", available at: https://www.nsta.org/about/positions/e-learning.aspx (accessed 30 May 2021).

Raja, R. and Nagasubramani, P.C. (2018), "Impact of modern technology in education", Journal of Applied and Advanced Research, Vol. 3 No. 1, pp. 33-35, doi: 10.21839/jaar.2018.v3S1.165.

Svensson, O.H., Adawi, T., Lundqvist, M. and Middleton, K.W. (2020), "Entrepreneurial engineering pedagogy: models, tradeoffs and discourses", European Journal of Engineering Education, Vol. 45 No. 5, pp. 691-710, doi: 10.1080/03043797.2019.1671811.

Violante, M.G., Vezzetti, E. and Piazzolla, P. (2019). "Interactive virtual technologies in engineering education: Why not $360^{\circ}$ videos?”, International Journal on Interactive Design and Manufacturing (IJIDeM), Vol. 13 No. 2, pp. 729-742, doi: 10.1007/s12008-019-00553-y.

Violante, M.G., Moos, S. and Vezzetti, E. (2020), "A methodology for supporting the design of a learning outcomes-based formative assessment: the engineering drawing case study", European Journal of Engineering Education, Vol. 45 No. 2, pp. 305-327, doi: 10.1080/03043797.2019. 1622653 .

\section{Corresponding author}

El-Shaimaa Talaat Abumandour can be contacted at: elshaimaa.talaat@bibalex.org
Engineering education challenges using e-learning

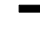

